\title{
RECURRENT VESICOURETHAL STENOSIS AFTER RADICAL PROSTATECTOMY: HOW TO TREAT IT?
}

\author{
FRANÇUALDO BARRETO, MARCOS DALL'OGLIO, MIGUEL SROUGI \\ Department of Urology, Paulista School of Medicine, Federal University of Sao Paulo, UNIFESP, Sao \\ Paulo, SP, Brazil
}

\begin{abstract}
Vesicourethral anastomotic stricture and urinary incontinence are severe complications of radical prostatectomy because they cause great impact in the quality of life. Three patients that presented these complications after prostate radical surgery were assessed retrospectively. To treat the stenosis of the vesicourethral anastomosis an urolume was placed and later on, an artificial sphincter AMS 800 was implanted to treat the resulting urinary incontinence.
\end{abstract}

Key words: prostatectomy; complications; urethral stricture; stents; urinary incontinence; prostheses and implants

Int Braz J Urol. 2005; 31: 552-4

\section{INTRODUCTION}

Some complications of radical prostatectomy, especially vesicourethral stricture and urinary incontinence, have interfered in the patient's quality of life, occurring in approximately $4 \%$ and $13 \%$ of the cases respectively (1). Vesicourethral stenosis treated with endoscopic uretrotomy is efficient in $85 \%$ of the cases, however in the rest of the cases, stenosis is severe and recurrent and transurethral procedures are not sufficient to assure bladder neck patency (1). For those individuals UroLume ${ }^{\circledR}$ is an alternative for treating the recurrent urethral stenosis and the artificial sphincter AMS 800 is the better choice to solve the consequent urinary incontinence.

We report our experience with a staged treatment of recurrent vesicourethral stricture and urinary incontinence after radical prostatectomy, using UroLume ${ }^{\circledR}$ followed by implant of an artificial sphincter AMS 800.

\section{CASE REPORT}

We present the cases of 3 men that presented recurrent vesicourethral stricture and urinary retention after radical retropubic prostatectomy. The mean time of surgical manipulation with urethral catheterization, urethrotomy and/or cystostomy, in all patients was of 140 days (Table-1). All patients were accessed through a clinical exam, urethroscopy and urethrography. When the presence of recurrent urethral stricture was verified, an UroLume ${ }^{\circledR}$ was indicated after 6 month of the radical prostatectomy (Table-2). After positioning the urethral stent with the inexorable evolution to urinary incontinence in all patients, the artificial sphincter AMS 800 was implanted after 4 months (Table-3). The mean followup was 24 months (12 to 40 months).

\section{COMMENTS}

Many are the determinant factors to vesicourethral stricture such as the anastomotic rup- 
Table 1 - Patients characteristics.

\begin{tabular}{lcclc}
\hline Patient & Age & Previous Radiotherapy & Manifestations & Catheterization Time \\
\hline 1 & 82 & No & Urinary retention & 147 days \\
2 & 64 & Yes & Urinary retention & 153 days \\
3 & 68 & No & Urinary retention & 120 days \\
\hline
\end{tabular}

Table 2 - Place and extension of the stenosis assessed through urethrography.

\begin{tabular}{llcc}
\hline Patient & Stenosis Site & Stenosis Extension & N of Internal Urethrotomies \\
\hline 1 & Bladder neck & $4 \mathrm{~cm}$ & 5 \\
2 & Bladder neck & $3 \mathrm{~cm}$ & 4 \\
3 & Bladder neck & $2 \mathrm{~cm}$ & 1 \\
\hline
\end{tabular}

Table 3 - Results of surgical treatment.

\begin{tabular}{lccccc}
\hline Patient & N of UroLume ${ }^{8}$ & UroLume ${ }^{\circledR}(\mathbf{c m})$ & AMS 800 (cm Ho $\mathbf{H}_{2} \mathbf{O}$ & Cuff & Continence \\
\hline 1 & 2 & 2.0 and 3.5 & 60 & $4.5 \mathrm{~cm}$ & Yes \\
2 & 2 & 3.5 and 3.5 & 60 & $4.5 \mathrm{~cm}$ & Yes \\
3 & 1 & 2.0 & 60 & $4.5 \mathrm{~cm}$ & Yes \\
\hline
\end{tabular}

ture, infection, extra-leaking of the urine in the anastomosis site and previous prostatic surgery. Treatment with urethral dilation is little effective while endoscopic uretrotomy reaches success around 66 to $85 \%$ (1). For the treatment of severe recurrent stenosis, UroLume ${ }^{\circledR}$ in association with an artificial sphincter AMS 800 has been a good solution with satisfaction rates of 88 to $100 \%(2,3)$. Generally, complete epithelization of the UroLume $\AA$ occurs between 3 to 6 months after its insertion (2), this being the reason why we recommend the introduction of an artificial sphincter AMS 800 after 4 months of the first procedure and its activation 6 weeks after the implant. To avoid problems of atrophy and urethral erosion, the pressure on the sphincter cuff should be between 60 $70 \mathrm{~cm} \mathrm{H} \mathrm{H}_{2} \mathrm{O}$, however, in those patients submitted to previous radiotherapy we can suggest a pressure of 51-60 $\mathrm{cm} \mathrm{H}_{2} \mathrm{O}(2)$.
When failure in minimally invasive procedures for treating vesicourethral stricture occurs, insertion of an urolume is indicated (2). The stent should be the smallest possible to try to preserve the sphincteric mechanism. However, its presence can impair the physiologic functioning of the sphincter, determining urinary incontinence. In these cases, it becomes necessary the insertion of an artificial sphincter to solve the urinary incontinence.

\section{CONFLICT OF INTEREST}

None declared.

\section{REFERENCES}

1. Catalona WJ, Carvalhal GF, Mager DE, Smith DS: Potency, continence and complication rates in 1,870 


\title{
VESICOURETHRAL STENOSIS AFTER PROSTATECTOMY
}

consecutive radical retropubic prostatectomies. J Urol. 1999; 162: 433-8.

2. Meulen T, Zambon JV, Janknegt RA: Treatment of anastomotic strictures and urinary incontinence after radical prostatectomy with urolume wallstent and AMS 800 artificial sphincter. J Endourol. 1999; 13: 517-20.
3. Elliott DS, Boone TB: Combined stent and artificial urinary sphincter for management of severe recurrent bladder neck contracture and stress incontinence after prostatectomy: a long-term evaluation. J Urol. 2001; 165: 413-5.

Received: May 3, 2005

Accepted after revision: September 30, 2005

\author{
Correspondence address: \\ Dr. Marcos F. Dall'Oglio \\ Rua Barata Ribeiro, 398 / 501 \\ São Paulo, SP, 01308-000, Brazil. \\ Fax: + $55113159-3618$ \\ E-mail: marcosdallogliouro@ terra.com.br
}

